\title{
"Marseilleviridae", a new family of giant viruses infecting amoebae
}

\author{
Philippe Colson • Isabelle Pagnier • Niyaz Yoosuf • \\ Ghislain Fournous $\cdot$ Bernard La Scola • \\ Didier Raoult
}

Received: 3 August 2012/ Accepted: 3 October 2012/Published online: 29 November 2012

(C) Springer-Verlag Wien 2012

\begin{abstract}
The family "Marseilleviridae" is a new proposed taxon for giant viruses that infect amoebae. Its first member, Acanthamoeba polyphaga marseillevirus (AP$\mathrm{MaV}$ ), was isolated in 2007 by culturing on amoebae a water sample collected from a cooling tower in Paris, France. APMaV has an icosahedral shape with a diameter of $\approx 250 \mathrm{~nm}$. Its genome is a double-stranded circular DNA that is 368,454 base pairs (bp) in length. The genome has a GC content of $44.7 \%$ and is predicted to encode 457 proteins. Phylogenetic reconstructions showed that APMaV belongs to a new viral family among nucleocytoplasmic large DNA viruses, a group of viruses that also includes Acanthamoeba polyphaga mimivirus (APMV) and the other members of the family Mimiviridae as well as the members of the families Poxviridae, Phycodnaviridae, Iridoviridae, Ascoviridae, and Asfarviridae. In 2011, Acanthamoeba castellanii lausannevirus (ACLaV), another close relative of $\mathrm{APMaV}$, was isolated from river water in France. The $\mathrm{ACLaV}$ genome is $346,754 \mathrm{bp}$ in size and encodes 450 genes, among which 320 have an APMaV protein as the closest homolog. Two other giant viruses closely related to $\mathrm{APMaV}$ and ACLaV have been recovered in our laboratory from a freshwater sample and a human stool sample using
\end{abstract}

P. Colson · I. Pagnier · N. Yoosuf · G. Fournous ·

B. La Scola $\cdot$ D. Raoult

URMITE UM63 CNRS 7278 IRD 198 INSERM U1905,

Aix-Marseille Université, Facultés de Médecine et de Pharmacie,

27 boulevard Jean Moulin, 13385 Marseille Cedex 05, France

P. Colson · B. La Scola · D. Raoult $(\bowtie)$

Pôle des Maladies Infectieuses et Tropicales Clinique et Biologique, Fédération de Bactériologie-Hygiène-Virologie, IHU Méditerranée Infection, Centre Hospitalo-Universitaire

Timone, Assistance Publique - Hôpitaux de Marseille,

264 rue Saint-Pierre, 13385 Marseille Cedex 05, France

e-mail: didier.raoult@gmail.com an amoebal co-culture method. The only currently identified hosts for "marseilleviruses" are Acanthamoeba spp. The prevalence of these viruses in the environment and in animals and humans remains to be determined.

\section{Introduction}

Acanthamoeba polyphaga marseillevirus (APMaV) was isolated in 2007 from water collected from a cooling tower in Paris, France, using a method based on Acanthamoeba polyphaga culture [1]. The name of this virus originates from the name of its amoebal host and the name of the French city, Marseille, where it was discovered. APMaV was described five years after the discovery of Acanthamoeba polyphaga mimivirus (APMV), the first giant virus identified using an amoebal co-culture method. APMV was revealed to be the largest known virus [2, 3]. APMaV was found to be smaller than APMV with respect to the sizes of the capsid and the genome. Nonetheless, with a capsid diameter of approximately $250 \mathrm{~nm}$ (Fig. 1) and a genome composed of 368,454 base pairs (bp) encoding 457 genes, APMaV represents a new giant virus. After the discovery of APMaV, other giant viruses were isolated from freshwater using the amoebal co-culture method and were briefly described in 2010 [4]. Among these new viruses, Cannes 8 virus $(\mathrm{Ca} 8 \mathrm{~V})$ is a close relative of $\mathrm{APMaV}$ based on the phylogeny of the B-family DNA polymerase gene [4]. In 2011, another large DNA virus, Acanthamoeba castellanii lausannevirus (ACLaV), was described, and this virus was determined to be a close relative of APMaV. ACLaV was isolated by culturing freshwater collected in 2005 from the Seine River in France on amoebae [5]. An additional close relative of $\mathrm{APMaV}$ was recently recovered in our laboratory from the stool of a young Senegalese 
man, and this new virus was named Senegal virus (SNGV) (Fig. 2) [6]. The genomes of Ca8V and SNGV have been sequenced on a 454-Roche GS20 instrument (Roche, USA) as described previously [1]. Additionally, the genome of the $\mathrm{Ca} 8 \mathrm{~V}$ isolated in our laboratory was sequenced on a SOLiD instrument (Life Technologies Corporation).

\section{Genomics of "marseilleviruses"}

The APMaV genome is a circular double-stranded DNA molecule of 368,454 base pairs (Table 1) [1]. Its GC content is $44.7 \%$. The APMaV genome harbors 457 open reading frames (ORFs) predicted to encode proteins with a size ranging from 50 to 1,537 amino acids. These ORFs represent $89 \%$ of the genome. APMaV was identified as representing a unique nucleocytoplasmic large DNA virus (NCLDV) family $[1,7]$. NCLDVs were described in 2001 as a monophyletic group of large viruses with a DNA genome. This group of viruses comprises the families Poxviridae, Asfarviridae, Iridoviridae and Phycodnaviridae, which were grouped together based on a set of core genes shared by all of the member viruses [8]. Later, APMV and then APMaV were found to be related to this group of viruses [1, 3], for which we recently proposed reclassification in a new viral order, "Megavirales" (talk.ictvonline.org/files/proposals/ taxonomy_proposals_fungal1/m/fung01/4261.aspx) [9]. All of these giant viruses share a common and very early ancestor based on phylogenetic and phyletic analysis of conserved and informational genes [7, 10, 11]. Among the NCLDVs, APMaV branched deeply with irido-/ascoviruses on the basis of the phylogenetic reconstruction of conserved
Fig. 1 Electron microscopy images of APMaV particles in a culture supernatant (scale bar represents $100 \mathrm{~nm}$ ) (a) and in Acanthamoeba sp (scale bar represents $200 \mathrm{~nm}$ ) (b), and of Acanthamoeba sp infected with APMaV (scale bar represents $2 \mu \mathrm{m})(\mathbf{c})$
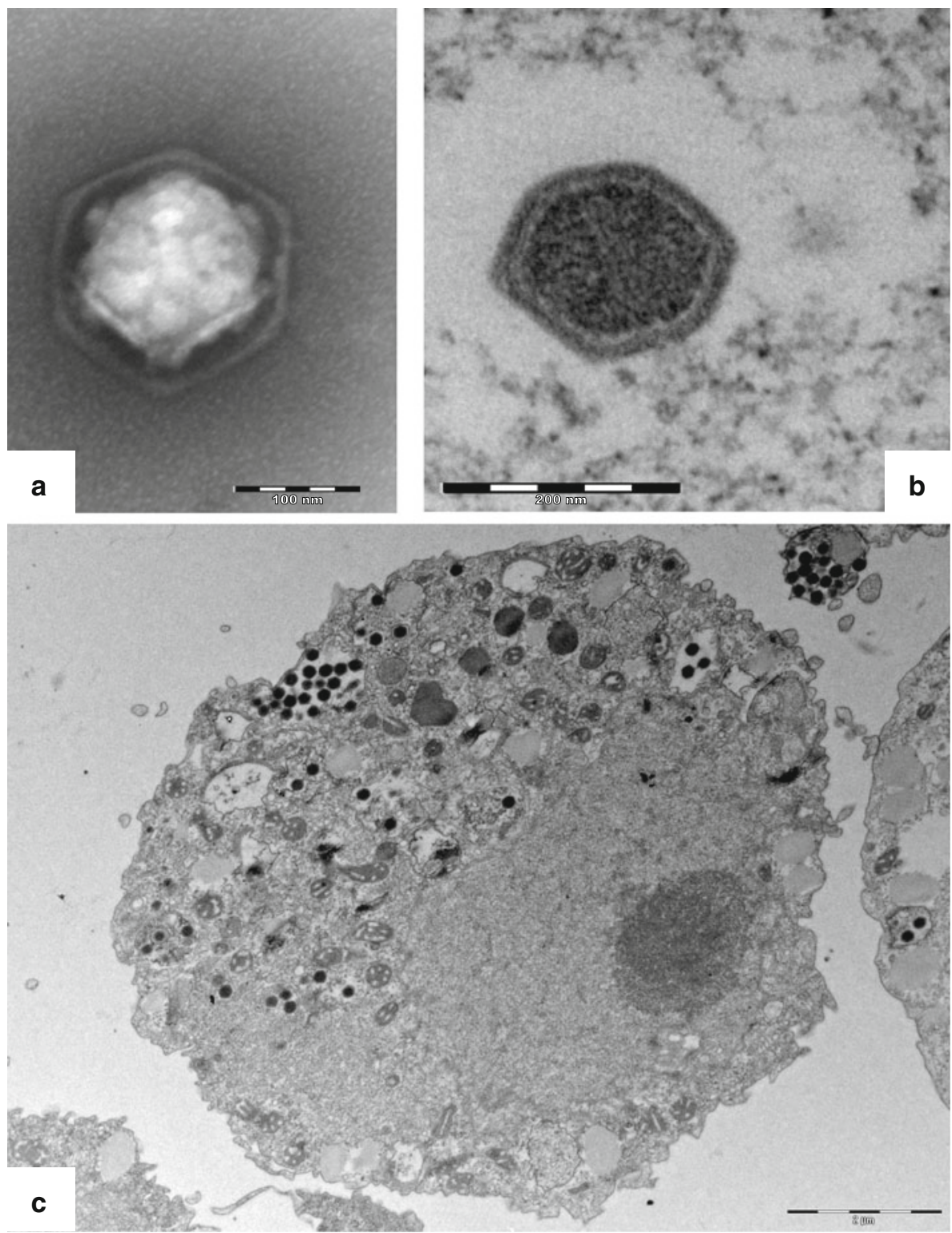

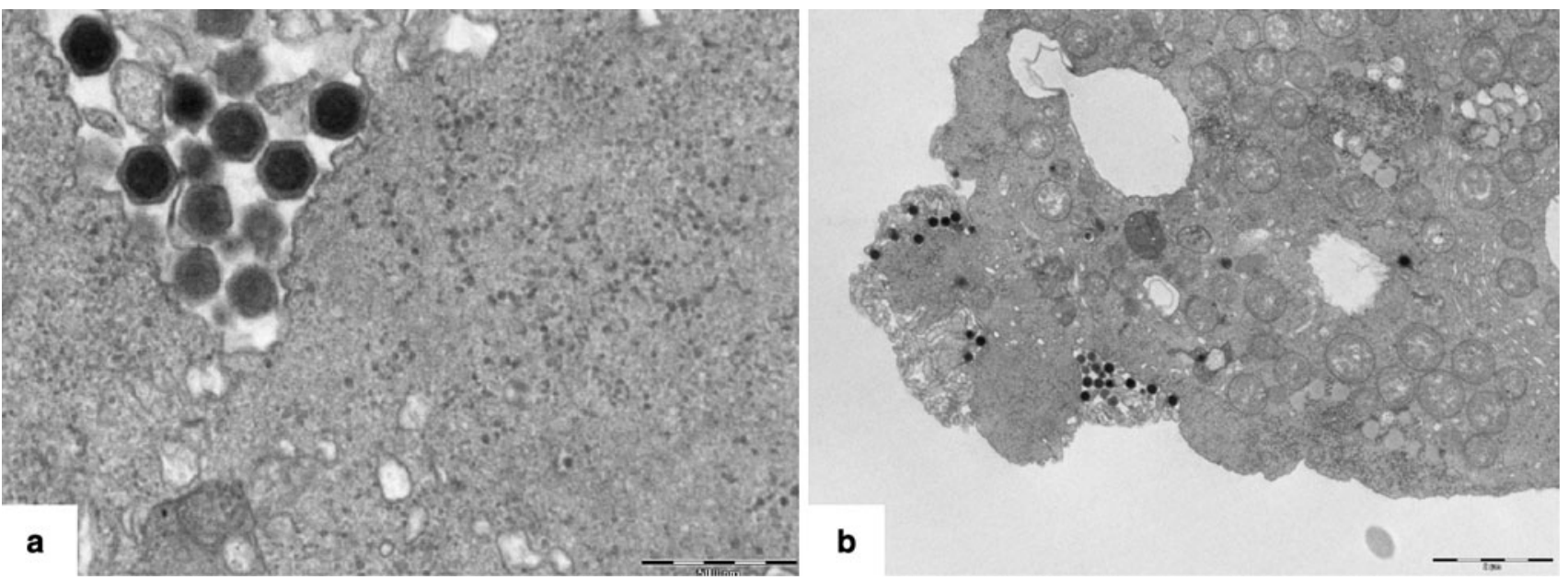

Fig. 2 Electron microscopy images of SNGV in Acanthamoeba polyphaga. a The scale bar represents $500 \mathrm{~nm}$. b The scale bar represents $2 \mu \mathrm{m}$

Table 1 Description of the primary features of the "Marseilleviridae" members

\begin{tabular}{|c|c|c|c|c|c|c|c|c|c|}
\hline Name & Source & $\begin{array}{l}\text { Country/ } \\
\text { region }\end{array}$ & $\begin{array}{l}\text { Capsid size } \\
(\mathrm{nm})\end{array}$ & $\begin{array}{l}\text { Genome GenBank } \\
\text { accession no. }\end{array}$ & $\begin{array}{l}\text { Date of } \\
\text { creation }\end{array}$ & $\begin{array}{l}\text { Genome } \\
\text { topology }\end{array}$ & $\begin{array}{l}\text { Genome } \\
\text { size (bp) }\end{array}$ & $\begin{array}{l}\text { Number of } \\
\text { genes }\end{array}$ & References \\
\hline APMaV & $\begin{array}{c}\text { Cooling } \\
\text { tower }\end{array}$ & $\begin{array}{l}\text { France } \\
\text { (Paris) }\end{array}$ & 250 & NC_013756 & $\begin{array}{r}25 / 01 / \\
2010\end{array}$ & Circular & 368,454 & 457 & {$[1]$} \\
\hline ACLaV & River (Seine) & France & $190-220 \mathrm{~nm}$ & NC_015326 & $\begin{array}{r}01 / 04 / \\
2011\end{array}$ & $\begin{array}{l}\text { Linear/ } \\
\text { circular }\end{array}$ & 346,754 & 450 & {$[5]$} \\
\hline $\mathrm{Ca} 8 \mathrm{~V}$ & $\begin{array}{c}\text { Cooling } \\
\text { tower }\end{array}$ & $\begin{array}{l}\text { France } \\
\quad \text { (Cannes) }\end{array}$ & 180 & JF979175.1 $1^{\mathrm{a}}$ & $\begin{array}{r}30 / 06 / \\
2012\end{array}$ & - & 374,039 & - & {$[4]$} \\
\hline SNGV & $\begin{array}{l}\text { Human stool } \\
\text { sample }\end{array}$ & Senegal & 210 & JF909596-JF909602 & $\begin{array}{r}13 / 09 / \\
2011\end{array}$ & - & 372,690 & - & {$[6]$} \\
\hline
\end{tabular}

${ }^{\text {a }}$ GenBank accession no. corresponds to the B-family DNA polymerase gene

genes $[1,7]$. In contrast, a comparison of the NCLDV gene repertoires instead grouped APMaV with APMV and Acanthamoeba polyphaga mamavirus (APMV2). The analysis of the APMaV genome has highlighted its mosaicism and the role of the amoeba as a biological niche for gene acquisition and exchange between sympatric bacteria, viruses and their amoebal hosts $[1,12]$. Thus, on the basis of phylogenetic analysis, the APMaV genome contains 51 genes $(11 \%)$ of probable NCLDV origin, $49(11 \%)$ of probable bacterial or bacteriophage origin, and $85(19 \%)$ of probable eukaryotic origin [1]. A total of 49 proteins have been identified in purified APMaV virions [1]. These proteins have been linked to several functional categories and include NCLDV core proteins, including the capsid protein. Of note, APMaV messenger RNAs, including transcripts encoding the DNA polymerase and the capsid, were found to be encapsidated in the virions.

The ACLaV genome is 346,754 bp in length, and its GC content is $42.9 \%$ [5]. It can be circular molecule or a linear DNA molecule with terminal repeats. This genome harbors 450 ORFs that cover $93 \%$ of the genome and have a mean length of $716 \mathrm{bp}$. ACLaV encodes homologs for all of the NCLDV core genes detected in APMaV. The phylogenetic analyses published previously showed that APMaV and ACLaV make up a new viral family among the nucleocytoplasmic large DNA viruses (NCLDVs) $[1,5,7,10]$. This family structure has been well established in several studies using several conserved proteins, including those encoded by NCLDV core genes. Although comparative genomics and phylogenetic reconstructions have shown that $\mathrm{ACLaV}$ is a close relative of $\mathrm{APMaV}$ and that both viruses belong to the same family [5], the genomes of these two giant viruses display considerable differences [5] (Figs. 3, 4). Indeed, a total of $332 \mathrm{ACLaV}$ proteins $(73.8 \%$ of the putative proteome) display significant similarity to proteins in the NCBI non-redundant sequence database, and among those proteins, only 320 (71.1\%) have an APMaV protein as the best BLASTp hit. In addition, comparative analysis of the ACLaV and AP$\mathrm{MaV}$ genomes revealed a $150-\mathrm{kb}$ region with poor synteny with many hypothetical proteins, followed by a $200-\mathrm{kb}$ region with a higher level of synteny (Figs. 3, 4), [5]. 
Only two-thirds of the ACLaV and APMaV proteins share a best reciprocal BLAST hit.

Another giant virus, Cannes 8 virus $(\mathrm{Ca} 8 \mathrm{~V})$, has been isolated in our laboratory from a freshwater sample using amoebal culture, and this virus has been found to be closely related to APMaV and ACLaV based on phylogenetic reconstructions (Table 1) [4]. Moreover, we obtained the first isolate of a giant virus infecting amoebae from a human sample, a stool sample from a young Senegalese man [6]. The genome (accession numbers JF909596-JF909601) of this giant virus, named Senegal virus (SNGV), has a size of approximately $373 \mathrm{kbp}$ (in the same range as those of APMaV and ACLaV). The analysis of the genomes of SNGV and Ca8V demonstrated that they are bona fide new members of the proposed family "Marseilleviridae" (talk. ictvonline.org/files/proposals/taxonomy_proposals_fungal1/ $\mathrm{m} /$ fung01/4262.aspx). Nonetheless, the genomes of SNGV and $\mathrm{Ca} 8 \mathrm{~V}$ display some differences compared with the genomes of APMaV and ACLaV (Fig. 4). The number of bidirectional best hits for APMaV and other members of the family "Marseilleviridae" tentatively ranges from 300 to 399. Overall, the ranges in size and in the number of genes for these new members of the family "Marseilleviridae" are similar to those of APMaV and ACLaV. At the present time, we propose defining only one genus, named "Marseillevirus". The species "Marseillevirus marseillevirus" is assigned to this genus and has one member, $\mathrm{APMaV}$, while the "marseilleviruses" ACLaV, SNGV and Ca8V remain presently unassigned until additional "marseilleviruses" are described.

Members of the family "Marseilleviridae" (the "marseilleviruses"), like those of the family Mimiviridae (the mimiviruses) and other NCLDV families, do not meet the usual criteria quoted by Lwoff to define viruses [13], and the outstanding characteristics of these viruses led us recently to propose a new order made up of these giant viruses [9].

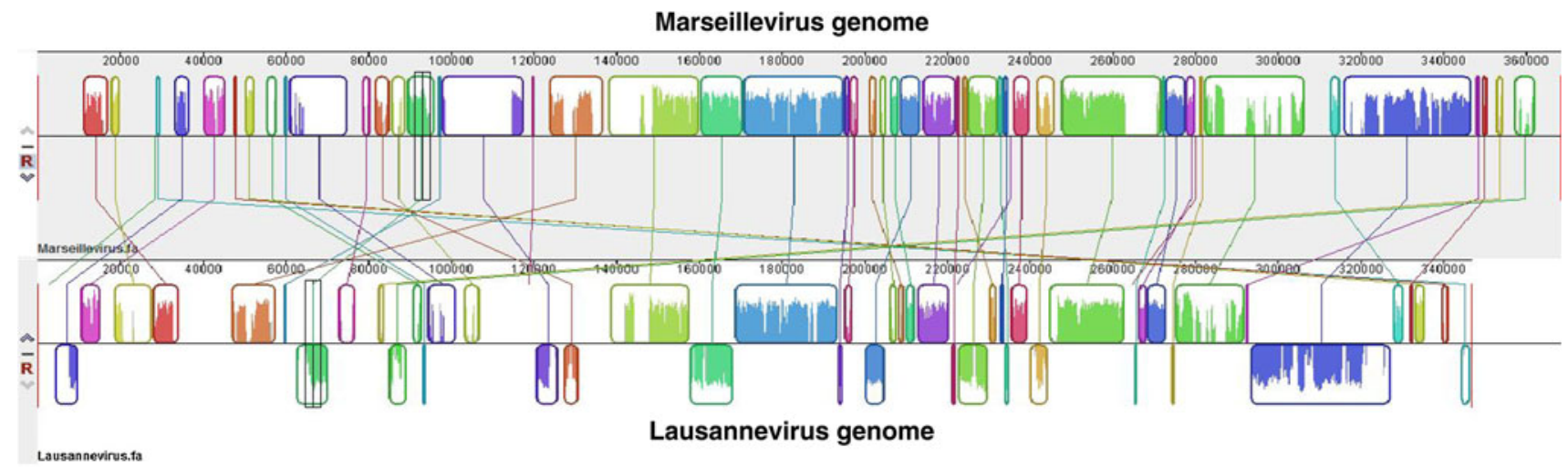

Fig. 3 Comparison and gene alignment of the genomes of APMaV and ACLaV using Mauve software [14]. Colored outlined blocks surround regions of the genome sequence that aligned to part of the other genome. The colored bars inside the blocks are related to the level of sequence similarity. Lines link blocks with homology between two genomes. Regions that are inverted relative to the other genome are shifted below a genome's center axis
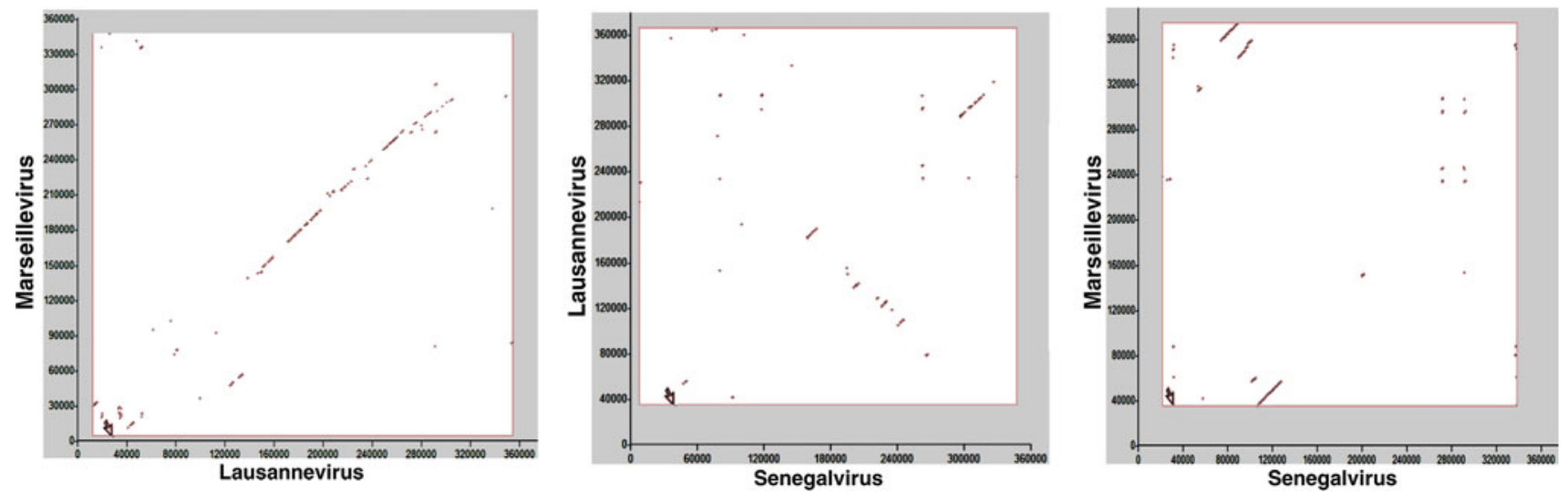

Fig. 4 Dot plots for the comparisons of the APMaV, ACLaV, and SNGV genomes using Owen software [15] 

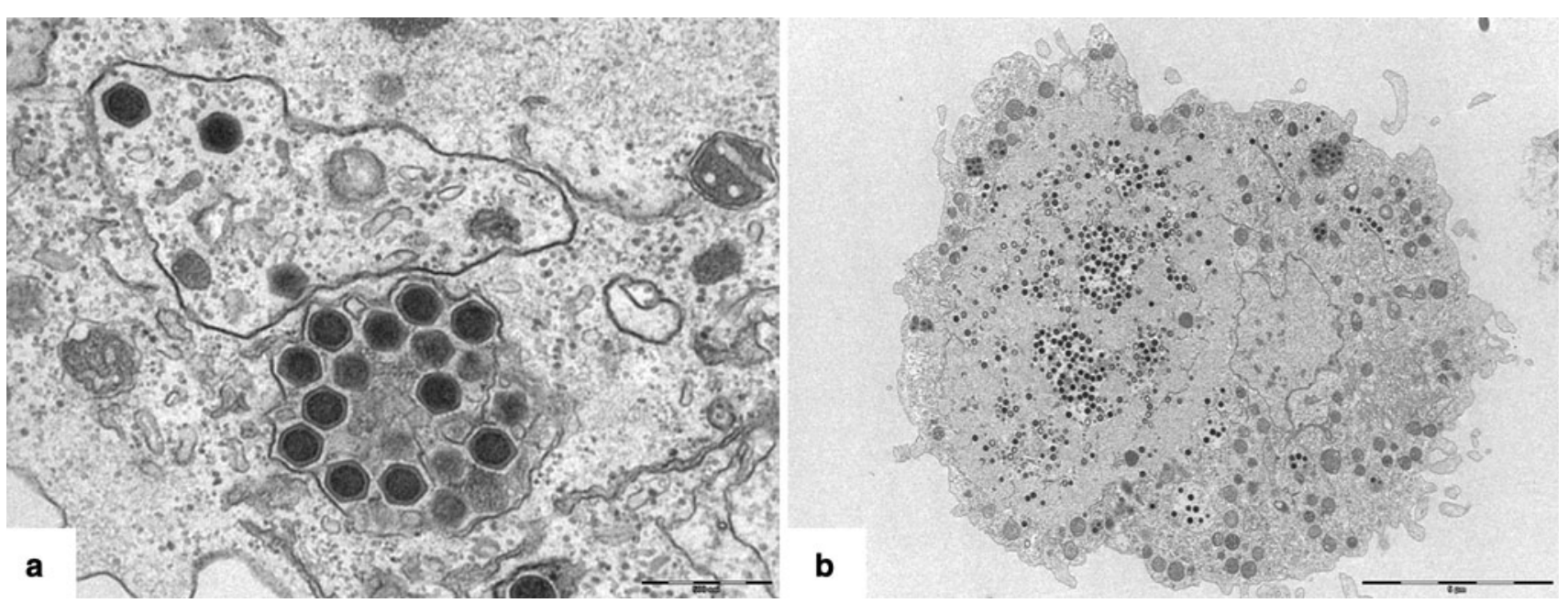

Fig. 5 Electron microscopy images of Ca8V in Acanthamoeba polyphaga (scale bar represents $500 \mathrm{~nm}$ ) (a) and of Acanthamoeba polyphaga infected with Ca8V (scale bar represents $5 \mu \mathrm{m}$ ) (b)

\section{Morphological properties}

APMaV, ACLaV, SNGV and Ca8V share similar morphological features, including the size of their capsids, which ranges from 190 to $250 \mathrm{~nm}$ (Fig. 1, 2, 5; Table 1). APMaV has an icosahedral shape and a diameter of $\approx 250 \mathrm{~nm}$ (Table 1; Fig. 1) [1]. The capsid shell has a thickness of $\approx 10 \mathrm{~nm}$, and 12-nm-long fibers with globular ends are present at the viral surface. A membrane may surround the nucleocapsid, which is separated from the capsid shell by a gap of $\approx 52 \mathrm{~nm}$. For all members of the family "Marseilleviridae", viral factories can be observed during the replication cycle. These viral factories have different appearances than those observed for APMV and APMV2, tending to be more widely distributed in the amoebal cytoplasm.

\section{Properties in culture}

All of the currently identified members of the family "Marseilleviridae" have Acanthamoeba spp. as their hosts and were isolated by culturing samples on these amoebae. In amoebal culture, APMaV enters the amoeba 30-60 min post-infection (p.i.) [1]. Later, a viral factory appears close to the nucleus of the amoeba. Capsid assembly and viral genome encapsidation are observed simultaneously in these viral factories, leading to mature and immature AP$\mathrm{MaV}$ particles. The replication cycle is complete at $5 \mathrm{~h} \mathrm{p.i,}$ which is a short period of time compared to that observed for APMV. The morphology of the host-cell nucleus changes considerably between $30 \mathrm{~min}$ and $2.5 \mathrm{~h}$ p.i. Regarding ACLaV, a few viral particles are present $30 \mathrm{~min}$ p.i [5]. After an eclipse phase, viruses can be observed again, in large vesicles, at $4 \mathrm{~h}$ p.i., and they fill the entire amoeba at $8 \mathrm{~h}$ p.i. before amoebal lysis at $16 \mathrm{~h}$ p.i.

\section{Prevalence, host, and pathogenicity}

The prevalence of "marseilleviruses" in environmental samples is currently unknown. Of note, four of these viruses were recently recovered from 103 water samples [4]. The only currently identified hosts for "marseilleviruses" are Acanthamoeba spp. [1, 4, 5]. No data are currently available on the prevalence of "marseilleviruses" in human or animal samples, and no pathogenic role has been demonstrated to date, but one virus belonging to the family "Marseilleviridae", SNGV, has been isolated from a human stool sample [6].

\section{Conclusion}

Acanthamoeba polyphaga marseillevirus (APMaV) and its close relatives exhibit remarkable features that are shared by mimiviruses and have contributed to a considerable increase in the interest in NCLDVs and to the better delineation of this group of giant viruses, for which we have recently proposed a new viral order named "Megavirales" $[1,5,9]$. The family "Marseilleviridae" would be included in the order "Megavirales". Further isolates will most likely be described that will be closely related to APMaV. We are performing comparative genomics analysis of the genomes of new putative "marseilleviruses" and will submit these new genomes to sequence databases. We believe that these viruses should be linked to a viral family. 
Conflict of interest All of the authors declare that they have no potential conflict of interest.

\section{References}

1. Boyer M, Yutin N, Pagnier I, Barrassi L, Fournous G, Espinosa L, Robert C, Azza S, Sun S, Rossmann MG, Suzan-Monti M, La Scola B, Koonin EV, Raoult D (2009) Giant Marseillevirus highlights the role of amoebae as a melting pot in emergence of chimeric microorganisms. Proc Natl Acad Sci USA 106:2184821853

2. La Scola B, Audic S, Robert C, Jungang L, de Lamballerie X, Drancourt M, Birtles R, Claverie JM, Raoult D (2003) A giant virus in amoebae. Science 299:2033

3. Raoult D, Audic S, Robert C, Abergel C, Renesto P, Ogata H, La Scola B, Suzan M, Claverie JM (2004) The 1.2-megabase genome sequence of Mimivirus. Science 306:1344-1350

4. La Scola B, Campocasso A, N'Dong R, Fournous G, Barrassi L, Flaudrops C, Raoult D (2010) Tentative characterization of new environmental giant viruses by MALDI-TOF mass spectrometry. Intervirology 53:344-353

5. Thomas V, Bertelli C, Collyn F, Casson N, Telenti A, Goesmann A, Croxatto A, Greub G (2011) Lausannevirus, a giant amoebal virus encoding histone doublets. Environ Microbiol 13:14541466

6. Lagier JC, Armougom F, Million M, Hugon P, Pagnier I, Robert C, Bittar F, Fournous G, Gimenez G, Maraninchi M, Trape JF,
Koonin E, Koonin EV, La Scola B, Raoult D (2012) Microbial culturomics: paradigm shift in the human gut microbiome study. Clin Microbiol Infect (in press)

7. Koonin EV, Yutin N (2010) Origin and evolution of eukaryotic large nucleo-cytoplasmic DNA viruses. Intervirology 53:284-292

8. Iyer LM, Aravind L, Koonin EV (2001) Common origin of four diverse families of large eukaryotic DNA viruses. J Virol 75:11720-11734

9. Colson P, de Lamballerie X, Fournous G, Raoult D (2012) Reclassification of giant viruses composing a fourth domain of life in the new order Megavirales. Intervirology 55(5):321-332

10. Yutin N, Wolf YI, Raoult D, Koonin EV (2009) Eukaryotic large nucleo-cytoplasmic DNA viruses: clusters of orthologous genes and reconstruction of viral genome evolution. Virol J 6:223

11. Boyer M, Madoui MA, Gimenez G, La Scola B, Raoult D (2010) Phylogenetic and phyletic studies of informational genes in genomes highlight existence of a 4 domain of life including giant viruses. PLoS One 5:e15530

12. Raoult D, Boyer M (2010) Amoebae as genitors and reservoirs of giant viruses. Intervirology 53:321-329

13. Lwoff A (1957) The concept of virus. J Gen Microbiol 17:239-253

14. Darling AC, Mau B, Blattner FR, Perna NT (2004) Mauve: multiple alignment of conserved genomic sequence with rearrangements. Genome Res 14:1394-1403

15. Ogurtsov AY, Roytberg MA, Shabalina SA, Kondrashov AS (2002) OWEN: aligning long collinear regions of genomes. Bioinformatics 18:1703-1704 